JEECOM, Vol. 1, No. 1, Oktober 2019

\title{
PENAMBAHAN SEAL AIR PADA SENSOR CHUTEPLUG DAN DISCHARGE COAL FEEDER UNTUK MENCEGAH MWH LOSSES DI PLTU PAITON $1 \& 2$
}

\author{
Ila Indira Pratiwi ${ }^{1)}$, Sulistiyanto. ${ }^{2)}$, Moh. Bachrudin ${ }^{3)}$ \\ Program Studi Teknik Elektro Fakultas Teknik Universitas Nurul Jadid \\ Karanganyar Paiton Probolinggo \\ Email: ilaindirap@gmail.com, sulistiyanto@ymail.com, bachrudin@gmail.com
}

\begin{abstract}
ABSTRAK
Data MWH losses yang didapat dari laporan pareto loss output menunjukkan bahwa jumlah frekuensi peralatan yang mengalami trip/gangguan paling banyak adalah coal feeder Dari berbagai penyebab trip coal feeder, frekuensi terbanyak disebabkan karena discharge plug. Terdapat 2 kondisi yang dapat membuat Trip coal feeder karena discharge plugged, yang pertama kondisi aktual batubara plugged pada discharge coal feeder sehingga sensor chute plug bekerja saat tertimbun batubara. Kondisi yang kedua kondisi tidak aktual (alarm palsu) yaitu sensor chute plug kotor terkena debu batubara dimana kondisi discharge coal feeder tidak ada batubara plugged. Penyebab terbesar terjadinya plugging di coal feeder dikarenakan kondisi batu bara yang basah dan lengket serta berdebu. Untuk mencegah hal tersebut solusi yang bisa dilaksanakan adalah dengan penambahan seal air pada discharge coal feeder dan sensor chute plug. Dengan menambahkan seal air maka dapat mengurangi frekuensi failure pada coal feeder sehingga meningkatkan keandalan dari pada coal feeder.
\end{abstract}

Kata kunci: Coalfeeder, Plugging, Seal air, Sensor Chute Plug

\section{PENDAHULUAN}

\subsection{Latar Belakang Masalah}

PT. PJB PLTU Paiton Unit $1 \& 2$ selaku anak perusahaan PT.PLN ikut berkontribusi dalam penurunan BPP. Langkah yang diambil oleh PLTU Paiton Unit 1\&2 yaitu dengan program Coal Switching.

Coal Switching merupakan program merubah nilai kalori bahan bakar batubara dari nilai 5000 kalori menjadi 4500 kalori. Program coal switching PLTU Paiton Unit 1\&2 yang diawali pada bulan Januari 2018 terbukti berhasil menurunkan BPP. Akan tetapi perubahan nilai kalori ini berdampak pada pengoperasian dan kondisi beberapa peralatan terutama pada peralatan sistem bahan bakar batubara.

Lla Indira : Penambahan Seal Air Pada ...
Kondisi setiap peralatan yang mengalami trip/gangguan akan berdampak pada bertambahnya mega watt hour (MWH) losses. MWH losses adalah hilangnya jumlah kesempatan produksi listrik yang dihasilkan dalam periode tertentu karena terjadi trip/gangguan peralatan yang menyebabkan derating atau menurunnya daya mampu netto. Sebagai langkah usaha dalam mencegah bertambahnya MWH losses yaitu salah satunya dengan cara fokus pada peralatan yang menyumbang jumlah frekuensi trip paling banyak.

Data MWH losses yang didapat dari laporan pareto loss output menunjukkan bahwa jumlah frekuensi peralatan yang mengalami trip/gangguan paling banyak adalah coal feeder. Tercatat januari 2017 
hingga juni 2018 jumlah trip pada coal feeder mencapai 124 kali dengan kerugian $\mathrm{MWH}$ losses5.634 MWH [1]. Dari berbagai penyebab trip coal feeder, frekuensi terbanyak disebabkan karena discharge plug. Terdapat 2 kondisi yang dapat membuat Trip coal feeder karena discharge plugged, yang pertama kondisi aktual batubara plugged pada discharge coal feeder sehingga sensor chute plug bekerja saat tertimbun batubara. Kondisi yang kedua kondisi tidak aktual (alarm palsu) yaitu sensor chute plug kotor terkena debu batubara dimana kondisi discharge coal feeder tidak ada batubara plugged. Penyebab terbesar terjadinya plugging di coal feeder dikarenakan kondisi batu bara yang basah dan lengket serta berdebu.

Untuk mencegah plugging pada coal feeder dan mengurangi MWH losses, penulis tertarik untuk melakukan penelitian dengan mengambil judul "Penambahan Seal Air pada Sensor ChutePlug dan Discharge Coal Feeder untuk mencegah MWH Losses di PLTU Paiton Unit 1 \& 2".

\subsection{Rumusan Masalah}

Dalam penulisan laporan skripsi ini, penulis merumuskan beberapa masalah pokok yang akan dibahas:

1. Apa fungsi dan prinsip kerja dari coal feeder?

2. Bagaimana prinsip kerja dari sensor chute plug?

3. Apa yang menyebabkan plugging pada coalfeeder?

4. Bagaimana caramengurangi gangguan dan MWH losses yang disebabkan oleh plugging padacoal feeder?

\subsection{Tujuan Penelitian}

Tujuan dari penelitian dalam skripsi ini adalah:

1. Untuk mengetahui dan memahami fungsi dan prinsip kerja dari coal feeder.

2. Untuk mengetahui prinsip kerja dari sensor chute plug.

Lla Indira : Penambahan Seal Air Pada ...
3. Untuk mengetahui penyebab plugging pada coalfeeder.

4. Untuk mengurangi gangguan dan $\mathrm{MWH}$ losses yang disebabkan oleh plugging pada coalfeeder.

\subsection{Batasan Masalah}

Untuk mencapai tujuan yang diharapkan dan agar isi serta pembahasan mengenai skripsi menjadi terarah, pembahasan hanya mengenai perlunya penambahan alat seal air pada sensor chuteplug dan discharge coal feeder.

\subsection{Manfaat Penelitian}

Adapun manfaat dari hasil penelitian yang diperoleh adalah sebagai berikut:

1. Dapat mengetahui dan memahami fungsi dan prinsip kerja dari coalfeeder.

2. Dapat mengetahui mengetahui prinsip kerja dari sensor chute plug.

3. Dapat mengetahui penyebab plugging pada coal feeder.

4. Dapat mengurangi gangguan dan MWH losses yang disebabkan oleh plugging pada coalfeeder.

\section{KAJIAN PUSTAKA}

\subsection{Penelitian Terdahulu}

Penelitian di PLTU Suralaya 1 - 4 dengan judul "Metode re-startingcoal feeder untuk penanggulangan gangguan coal plugging pada inlet coal feeder", dimana penelitian ini membahas tentang penanggulangan gangguan coal plugging pada inlet coal feeder yang dapat dilakukan dalam kondisi sistem coal feeder dan pulverizer masih beroperasi. Ketika terjadi coal plugging, operator control room (CCR) akan hentikan operasi coal feeder dan operator lokal bisa menanggulangi coal plugging dengan mengoperasikan vibrator dan juga dengan cara konvensional, yaitu memukul dengan palu [2]. Dibandingkan dengan metode penambahan seal air pada sensor chute plug dan discharge coal feeder, metode ini banyak memiliki kekurangan dikarenakan sangat menguras tenaga serta 
tidak dapat mencegah plugging dikarenakan metode ini diaplikasikan ketika terjadi plugging.

Penelitian di PLTU Tarahan dengan judul "Modifikasi line coal feeder dengan penambahan sistem pneumatic pada Boiler CFB Tarahan", dimana penelitian ini membahas tentang plugging pada discharge coal feeder yang disebabkan oleh semakin banyaknya flow rate batubara basah yang mengakibatkan semakin besar pula tahanan gesek yang ditimbulkan, hal ini terjadi karena luas permukaan kontak juga semakin besar antara batubara dengan dinding saluran. Dimana plugging tesebut dapat ditanggulangi dengan cara modifikasi $\mathbf{2 . 2}$ penambahan sistem pneumatic atau sistem udara bertekanan yang bertujuan untuk memperbesar gaya dorong partikel batubara menuju ruang bakar. [2]. Biaya yang diperlukan dalam metode ini cukup besar dikarenakan menambahkan sistem udara bertekan pada proses aliran batubara menuju ke ruang bakar, serta memiliki risiko yang tinggi. Sedangkan biaya yang diperlukan dalam penambahan seal air pada sensor chute plug dan discharge coal feeder tidak besar dan tidak memiliki risiko yang tinggi.

Penelitian di PLTU Indramayu dengan judul "Modifikasi plugging detector pada outlet coal feeder untuk mengurangi derating unit PLTU Indramayu", dimana proses pengolahan batubara di PLTU Indramayu menggunakan peralatan seperti conveyor, crusher, coal bunker, coal feeder, dan coal pulverizer. Permasalahan yang sering terjadi saat musim hujan pada peralatan coal feeder adalah terjadinya plugging pada outletcoal feeder yang dapat menyebabkan coal feeder trip, sehingga menyebabkan unit mengalami derating. Kondisi ini disebabkan karena peralatan plugging detector yang terpasang kurang efektif, sehingga tidak dapat mendeteksi terjadinya plugging batubara pada outlet coal feeder lebih dini.Untuk mengoptimalkan fungsi peralatan plugging detector pada outlet coal feeder, maka dilakukan modifikasi penambahan peralatan pluggingdetector yang dipasang pada posisi bawah outlet damper, dengan tujuan agar dapat mendeteksi kejadian plugging lebih dini, sehingga dapat dilakukan evakuasi batubara lebih cepat dan bisa mengurangi terjadinya unit derating. Dengan penambahan peralatan plugging detector, maka dapat diketahui lebih dini terjadinya plugging pada outlet coal feeder dan bisa segera dilakukan tindakan penanganan berupa evakuasi batubara, sehingga dapat mencegah derating akibat plugging [2]. Metode ini memerlukan biaya yang besar dikarenakan mengganti tipe sensor dan potensi terjadinya plugging masih bisa terjadi.

Hasil penelitian terdahulu merupakan referensi bagi peneliti untuk melakukan penelitian ini. Dalam penelitan initidak terdapat kesamaan permasalahan penelitian Teori Coal Feeder

\subsubsection{Fungsi Coal Feeder}

Coal feeder merupakan peralatan utama pada PLTU yang berfungsi untuk mengatur laju batubara yang dari coal bunker/silo menuju ke mill/pulverizer untuk dihaluskan.Coal feeder ini bertugas untuk mengatur banyak dan sedikitnya batubara yang masuk ke mill sesuai dengan kebutuhan bahan bakar yang digunakan dalam boiler[3].Kebutuhan akan bahan bakar sendiri sangat tergantung dengan besarnya daya yang dibangkitkan. Berikut merupakan gambaran mengenai coal feeder yang dijelaskan pada gambar 2.1. 


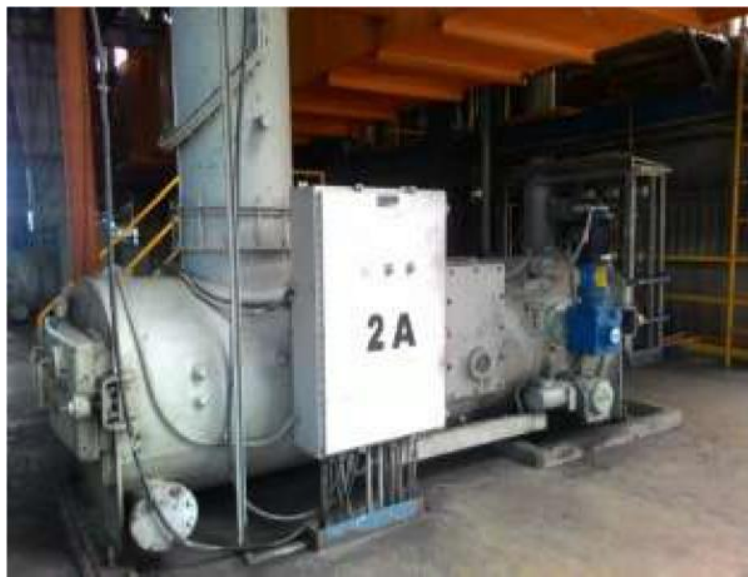

Gambar 2.1.Coalfeeder

Berdasarkan gambar 2.1 dijelaskan bahwa coal feeder yang digunakan PLTU Paiton Unit $1 \& 2$ adalah coal feeder yang berjenis gravimetric karena mempunyai tingkat akurasi yang tinggi jika dibandingkan dengan tipe volumetric [3]. Terdapat 10 coal feeder di PLTU Paiton Unit $1 \& 2$ dengan 5 buah coal feeder berada pada Unit 1 dan 5 buah coal feeder lagi berada pada Unit 2.

\subsubsection{Bagian Coal Feeder}

Berikut merupakan gambaran mengenai bagian-bagian coal feeder yang dijelaskan pada gambar 2.2

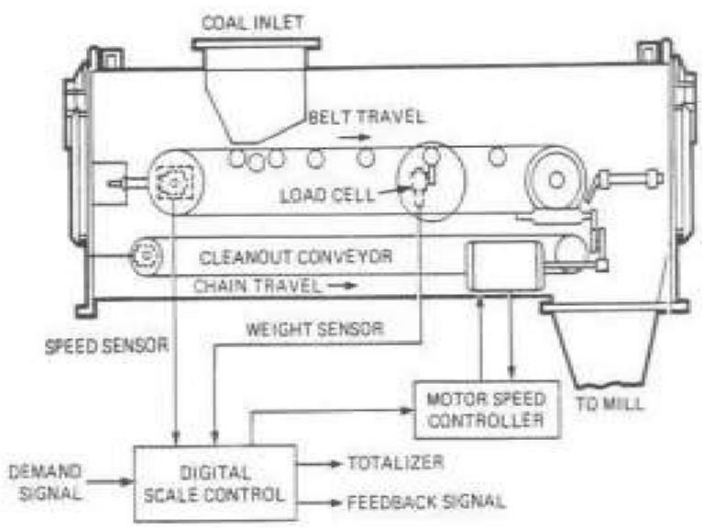

Gambar 2.2.Bagian - bagian coal feeder [3].

\subsubsection{Spesifikasi Coal Feeder}

Tabel 2.1.Spesifikasi Coal Feeder PLTU UP Paiton [3].

\begin{tabular}{|c|c|c|}
\hline NO. & KRITERIA & NILAI \\
\hline \multirow[b]{2}{*}{1} & \multicolumn{2}{|l|}{ Kondisi input } \\
\hline & $\begin{array}{l}\text { Gravimetric Feeder } \\
: \\
\text { Manufacturer } \\
\text { Model }\end{array}$ & $\begin{array}{l}\text { STOCK } \\
\text { Equipment } \\
\text { Company } \\
8424(610 \\
\mathrm{mm})\end{array}$ \\
\hline \multirow[b]{2}{*}{2} & \multicolumn{2}{|c|}{$\begin{array}{l}\text { Kondisi output dan ko mposisi } \\
\text { proses }\end{array}$} \\
\hline & $\begin{array}{l}\text { Maximum feedrate: } \\
\text { Minimum feedrate : } \\
\text { Input signal: } \\
\text { Output signal : }\end{array}$ & $\begin{array}{l}52 \mathrm{~T} / \mathrm{H} \\
12 \mathrm{~T} / \mathrm{H} \\
4-20 \mathrm{~mA} \\
4-20 \mathrm{~mA}\end{array}$ \\
\hline \multirow[b]{2}{*}{3} & \multicolumn{2}{|c|}{ Daftar spare part list $\mathrm{y}$ ang penting } \\
\hline & $\begin{array}{l}\text { Belt conveyor } \\
\text { Motion monitor } \\
\text { Fuse } 2 \text { A }\end{array}$ & $\begin{array}{l}\text { X940-0-145 } \\
\text { V/S } \\
\text { Z10624-2 }\end{array}$ \\
\hline
\end{tabular}

\section{METODE PENELITIAN}

\subsection{Rancangan Penelitian}

\subsubsection{Prinsip Kerja Coal Feeder}

Coal feeder merupakan peralatan utama pada PLTU yang berfungsi mengatur laju aliran batubara yang masuk ke mill untuk dihaluskan. Coal feeder bertugas mengatur banyak sedikitnya batubara sesuai dengan kebutuhan yang diinginkan, yakni besarnya daya yang ingin dibangkitkan dari suatu sistem PLTU. Berikut merupakan gambaran mengenai coal feeder di jelakan gbr 3.1 


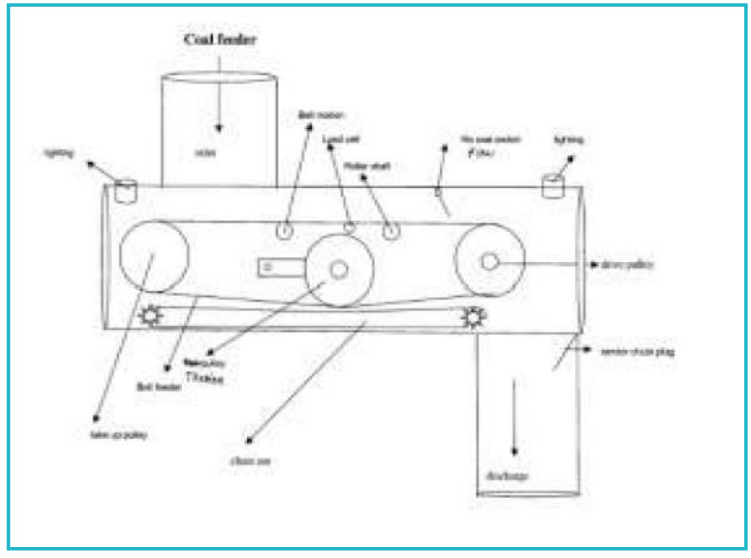

Gambar 3.1. Coal Feeder UP Paiton [3]. Pada gambar 3.1 dijelaskan bahwabelt feeder menerima batubara dari inlet coal feeder kemudian mengarahkan batubara menuju discharge coal feeder dan meneruskan aliran batubara tersebut ke mill. Pada discharge coal feeder terdapat sensor level switch yang befungsi sebagai proteksi apabila terjadi penumpukkan batubara (plugging) pada inlet mill hingga discharge coal feeder atau proteksi apabila terjadi plugging hanya pada discharge coal feeder.

\section{HASIL DAN PEMBAHASAN \\ 4.1 Hasil Penelitian}

\subsubsection{Laporan Operasi Tahun 2017 s/d Juni} 2018

Berikut merupakan gambar grafik laporan operasi tahun 2017 s/d juni 2018 yang dijelaskan pada gambar 4.2.

Berikut merupakan gambar grafik gangguan pada coal feeder tahun 2017 s/d juni 2018 yang dijelaskan pada gambar 4.2

\begin{tabular}{|c|c|c|c|c|c|c|c|c|c|c|}
\hline & Conl feteder & Ifedte & Fedete & Haxted: & God loted & wherter & a Cal fedede a & $a$ cod inder $x$ & Cool Fetede D & Lod latede \\
\hline 58 & 0 & 0 & 1 & 1 & 1 & 0 & 2 & 1 & 3 & 1 \\
\hline lastsus & 0 & 1 & 1 & 1 & 4 & 1 & 2 & 1 & 3 & 1 \\
\hline Saptate aris & 0 & 8 & 1 & 3 & 1 & 1 & 2 & 2 & $!$ & 0 \\
\hline 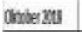 & 0 & 2 & 1 & 1 & 1 & 0. & 8 & 1 & 1 & 1 \\
\hline Herte Xas & 0 & 1 & 1 & 1 & 1 & 0 & 1 & 1 & 1 & 0 \\
\hline Deerbeizta & 1 & 1 & 1 & 1 & 1 & 1 & 1 & 1 & 1 & 1 \\
\hline Inaizus & 1 & 0 & 1 & 1 & $t$ & 0 & 1 & I & 1 & 2 \\
\hline Phorian & 0 & 0 & 1 & 1 & 1 & 0 & 1 & 1 & 1 & 0 \\
\hline lasidat & 1 & 0 & 2 & 1 & 1 & 0 & 1 & 1 & 1 & 1 \\
\hline frians & 0 & $\theta$ & 2 & 1 & 1 & 2 & 1 & 1 & 3 & 2 \\
\hline Hixas & 0 & 1 & 1 & 2 & 1 & 0 & 1 & 1 & 1 & 1 \\
\hline |xisls & 0 & 0 & 1 & 1 & 1 & 1 & 8 & 2 & $!$ & 1 \\
\hline
\end{tabular}

Lla Indira : Penambahan Seal Air Pada ...
Penambahan seal air pada sensor chute plug dan discharge coal feeder merupakan hal yang tepat dilakukan untuk mengatasi plugging secara aktual maupun tidak aktual. Plugging secara aktual dapat diatasi dengan penambahan seal air pada discharge coal feeder, dimana seal air yang digunakan pada discharge feeder berasal dari udara service. Berikut gambar mengenai pemasangan seal air pada discharge

coal feeder yang dijelaskan pada gambar 4.1.

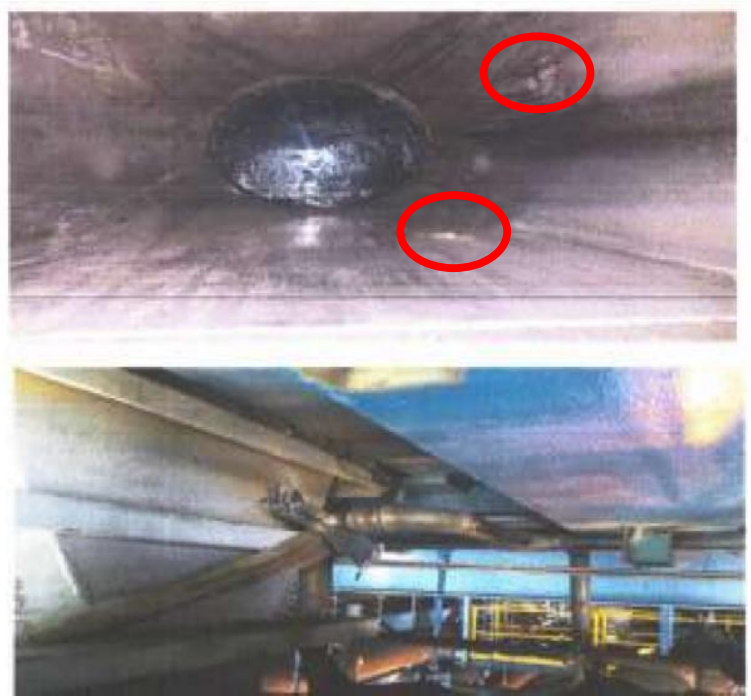

Gambar 4.1.Pemasangan seal air pada discharge coal feeder

\section{KESIMPULAN} [5].

Dari penambahan seal air pada sensor chute plug dan discharge coal feeder kemudian dilakukan pengujian dan analisa menghasilkan beberapa kesimpulan sebagai berikut: [6].

1. Penyebab coal feedertripkarena discharge plugged disebabkan karena debu batu bara yang menempel di sensor chute plug (kondisi tidak aktual) dan penumpukan batu bara di [7]. dicharge coal feeder (kondisi aktual). 
2. Alternatif solusi yang paling efektif untuk mencegah coal feeder trip akibat discharge plugged adalah dengan menambahkan seal air [8]. pada sensor chute plug dan dischargecoal feeder.

3. Setelah dilakukan evaluasi, penambahan seal air ini mampu mengurangi frekuensi trip coal [9]. feeder1A sebanyak 3x serta mengurangi MWH losses akibat plugging coal feeder $1 \mathrm{~A}$.

4. Discharge coal feeder dan sensor chute plug [10]. coal feeder 1A dapat di cleaning secara online.

\section{DAFTAR PUSTAKA}

Laporan Operasi PT.PJB UP Paiton tahun 2017 s/d 2018 Katalog amio PLN

Sargent \& Lundy Integ. 1993. Maintenance and Vendor Manual Volume 14. Jakarta: ABB Combustion Enineering system.

Hauser, Endress. 2012. "Solicap S FtI77". Endress hauser technical information solicap S FTI77. Switzerland. Ametek. 2008. "Ztron IV Point Level Control". Ametek Installation and operating instructions Ztron IV ${ }^{\mathrm{TM}}$ Point Level Control. Horsham.

Sargent \& Lundy. 1991. Manual book Service and instrument compressed air system volume 1. Jakarta: Ingersoll-Rand.

Sargent \& Lundy Integ. 1993. Maintenance and Vendor Manual Volume 7. Jakarta: ABB Combustion Enineering system.

Sargent \& Lundy Integ. 1993. Maintenance and Vendor Manual Volume 9. Jakarta: ABB Combustion Enineering system. Talla, Harli. (2014), "Karakteristik Batubara dan Pengaruhnya terhadap proses pencarian", dalam IEEE Reaktor, hal 267-271.

Lla Indira : Penambahan Seal Air Pada ...
IKP-17.1.1.204 :Cleaning Discharge\& Sensor Chute Plug Coal Feeder Secara Online 